\title{
Contabilidade de Custos e Formação do Preço de Venda: Um Estudo de Caso em uma Padaria
}

Citania Aparecida Pilatti Bortoluzzi Mestrado em Administração pela Universidade do Oeste de Santa Catarina - UNOESC Professora no Serviço Nacional de Aprendizagem Comercial - SENAC e Professora na Unidade Central de Educação - FAEM Faculdades Rua Coronel Passos Maia, 595. Centro. Xanxerê/SC. CEP: 89.820-000 E-mail: citaniapilatti@hotmail.com

Solange Chiossi Graduação em Ciências Contábeis pela Unidade Central de Educação - FAEM Faculdades

Agente de Atendimento Caixa Rua Hercílio Luz, 200, Centro. Arvoredo/SC. CEP: 89.778-000 E-mail: solangechiossi@gmail.com

Tiago Francisco Camargo Mestrado em Contabilidade e Administração pela Universidade Comunitária da Região de Chapecó - UNOCHAPECO - Universidade Federal Rio Grande Professor na Universidade Empresarial de Chapecó e Professor na Universidade Federal da Fronteira Sul - UFFS Rua Augusto Pompermayer, 149. Bairro Palmital. Chapeco/SC. CEP: 89.815-245 E-mail: tiago.camargo@uceff.edu.br

Leossania Manfroi Mestrado em Contabilidade pela Universidade Regional de Blumenau - FURB Professora na Unidade Central de Educação - FAEM Faculdades Travessa Tijucas, 109E, apto 102. Bairro Presidente Médici. Chapeco/SC. CEP 89.801307 E-mail: Leossania@uceff.edu.br

Juliano Correa Daleaste Mestrado em Administração pela Universidade do Oeste de Santa Catarina - UNOESC Professor na Unidade Central de Educação - FAEM Faculdades Rua: Lauro Muller, 767. Santa Maria. Chapecó/SC. CEP: 89.812-214 E-mail: daleaste@hotmail.com

\section{RESUMO}

Este estudo objetivou identificar os custos e a formação do preço de venda dos produtos de uma indústria de panificação localizada no município de Arvoredo - SC. O estudo foi realizado durante os meses de julho a outubro de 2017. Para atingir esse 
Contabilidade de Custos e Formação do Preço de Venda: Um Estudo de Caso em uma Padaria

Citania Aparecida Pilatti Bortoluzzi, Solange Chiossi, Tiago Francisco Camargo, Leossania Manfroi,

Juliano Correa Daleaste

objetivo, realizou-se um estudo de caso. A pesquisa caracteriza-se, quanto aos objetivos, como um estudo exploratório, e a coleta de dados desenvolveu-se com a aplicação de uma entrevista semiestruturada, observação e análise documental. Os resultados da pesquisa foram submetidos a tratamento quantitativo, por meio do método de custeio por absorção. Por meio dos dados levantados, foi possível identificar os custos e despesas da atividade, bem como sua alocação para cada produto, possibilitando formular o preço de venda e sua correta margem de contribuição. Dentre os principiais resultados evidenciados, constatou-se que havia diferenças entre o preço de venda orientativo e o praticado, sendo que, para os três produtos analisados, as margens de contribuição unitárias ficaram menores mediante o preço praticado do que pelo orientativo. Diante destes parâmetros, conclui-se que o empresário não possui o retorno da margem de lucro que ele projeta receber, evidenciado na DR (Demonstração de Resultado gerencial) que permitiu apurar uma diferença de 14,6\% a menor no lucro líquido, por não ser utilizada a precificação com as margens corretas indicadas pelo Markup, o que representa algumas ineficiências da gestão por não utilizar-se das ferramentas da contabilidade de custos para tais controles. Apesar disso, o empresário ainda não está tendo prejuízo, porém está perdendo a oportunidade de melhorar seus resultados. Ressalta-se a relevância que as informações oriundas da correta apuração dos custos de produção e, consequentemente, formação do preço de venda produz para auxiliar a empresa, gestores ou investidores a traçar suas estratégias, controlar seus custos e aproveitar, de maneira mais eficaz, os recursos financeiros disponíveis.

Palavras-chave: Contabilidade de custos. Classificação dos custos. Formação de preço.

\section{Cost Accounting and Price Formation: A Case Study in a Bakery}

\section{ABSTRACT}

This study aimed to identify the costs and the formation of the sale price of the products of a bakery industry located in the municipality of Arvoredo - SC. The study was carried out from July to October 2017. In order to achieve this objective, a case study was carried out. The research is characterized as to the objectives, as an exploratory study, and the data collection was developed with the application of a semi-structured interview, observation and documentary analysis. The research results were subjected to quantitative treatment, using the absorption costing method. Through the data collected it was possible to identify the costs and expenses of the activity as well as its allocation for each product, making it possible to formulate the selling price and its correct contribution margin. Among the main results evidenced, it was found that there were differences between the guide and the practiced selling price, and for the three products analyzed the unit contribution margins were lower through the price practiced than by the guide. In view of these parameters, it can be concluded that the entrepreneur does not have the return on the profit margin that he plans to receive, as 
Contabilidade de Custos e Formação do Preço de Venda: Um Estudo de Caso em uma Padaria

Citania Aparecida Pilatti Bortoluzzi, Solange Chiossi, Tiago Francisco Camargo, Leossania Manfroi,

Juliano Correa Daleaste

evidenced in the DR (Managerial Income Statement), which allowed a difference of less than $14.6 \%$ in net profit, as it is not pricing with the correct margins indicated by Markup was used, which represents some management inefficiencies for not using the cost accounting tools for such controls. Despite this, the entrepreneur is still not making a loss, but he is missing the opportunity to improve his results. The relevance that the information derived from the correct calculation of production costs and consequently formation of the selling price, produces to help the company, managers or investors to outline their strategies, control their costs and make the most effective use of financial resources is emphasized available.

Keywords: Cost accounting. Cost classification. Pricing.

\section{INTRODUÇÃO}

De acordo com o Instituto Tecnológico de Panificação e Confeitaria (ITPC), em 2017, as empresas deste segmento apresentaram crescimento de $3,2 \%$ em nível nacional, apresentando um faturamento projetado de $\mathrm{R} \$ 90,3$ bilhões. Segundo o Sebrae (2018), em Santa Catarina haviam 29.491 estabelecimentos deste segmento registrados, que foram responsáveis por 10.798 empregos diretos.

No entanto, este segmento vem sofrendo muitos impactos como: as alterações no comportamento do cliente, crescimento da concorrência, entrada de atacarejos, lojas de vizinhanças, conveniências e food-trucks (ambulantes). Por estes e demais motivos, evidencia-se a necessidade de conhecimento profundo e detalhado da estrutura de custos e despesas dessas relevantes e importantes organizações empresariais.

Para que seja possível administrar uma organização, as informações de custos têm papel relevante, pois atendem diversos usuários, e cada qual com propósitos diferentes de uso no âmbito do sistema empresa, dentre os quais os mais comuns são: custear estoques para fins de apuração de resultado de acordo com a legislação societária, cálculo de formação de preço de venda e planejamento, controle e tomada de decisão (Almeida \& Santos, 2007).

Diante de mercados cada vez mais competitivos, as organizações precisam estar sempre à frente da concorrência para se manterem atuantes e, sobretudo, com 
Contabilidade de Custos e Formação do Preço de Venda: Um Estudo de Caso em uma Padaria

Citania Aparecida Pilatti Bortoluzzi, Solange Chiossi, Tiago Francisco Camargo, Leossania Manfroi, Juliano Correa Daleaste

resultados positivos, em que o lucro possa ser alcançado, maximizando a produção e minimizando os custos e a perda. Desse modo, o gestor necessita de informações que o auxiliem na tomada de decisão, sendo que uma das informações indispensáveis é o conhecimento dos custos e a formação do preço (Niederle, 2012).

Com o advento da globalização, a facilidade de encontrar o produto desejado é cada vez maior. Sendo assim, para se tornarem mais atraentes, as empresas precisam de fatores que as diferenciem das demais. O conhecimento dos elementos de formação do preço de venda dos produtos e serviços constitui-se uma vantagem competitiva relevante para as organizações, partindo da premissa de que os clientes, o governo, os avanços tecnológicos são fatores que influenciam no crescimento e na existência da organização (Cunha \& Fernandes, 2007).

De acordo com Sepp, Manfroi, Theisen, Deil e Diel J. (2015), empresas enfrentam diversas dificuldades para se manterem atuantes no mercado. Um dos fatores recorrentes entre os empresários são os altos custos de produção e despesas de comercialização do produto final. Neste sentido, é de extrema importância que a gestão de custos esteja alinhada ao planejamento estratégico das indústrias e que seja uma ferramenta que auxilie na tomada de decisões mais corretas possíveis.

Conforme Silva Filho, Lagioia, Araújo e Carlos Filho (2015), compete à gestão da contabilidade de custos produzir informações capazes de otimizar a qualidade das decisões, auxiliando no controle dos processos da empresa e tornando a empresa mais competitiva. Ainda conforme os autores, os gestores devem ter o entendimento pleno do processo produtivo para o qual a entidade está inserida como atividade principal, alinhando tal entendimento aos conhecimentos das ferramentas de gestão de custos, conseguindo, por meio delas, definir estratégias para a formação do preço de venda, mantendo-se competitiva e lucrativa no mercado.

Estudos como de Hall, Costa, Kreuzberg, Moura e Hein (2012), Pelissari, Gonzalez e Vanalle (2011) procuraram identificar o uso e o conhecimento das informações contábeis como subsídios para tomada de decisão para a redução da mortalidade das empresas. No entanto, constataram que é muito limitada e inexpressiva 
Contabilidade de Custos e Formação do Preço de Venda: Um Estudo de Caso em uma Padaria

Citania Aparecida Pilatti Bortoluzzi, Solange Chiossi, Tiago Francisco Camargo, Leossania Manfroi,

Juliano Correa Daleaste

a quantidade de empreendedores que se utilizam desse critério para tomada de decisões. Por outro lado, muitas decisões são subsidiadas apenas com base na experiência operacional pessoal ou de terceiros, reduzindo drasticamente, dessa maneira, as possibilidades de tomar decisões com base em fatos e dados de seu próprio negócio.

Nesse contexto, surge a seguinte questão de pesquisa que se propõe investigar: Quais os custos que incidem na formação do preço de venda dos produtos de uma indústria de panificação localizada no município de Arvoredo - SC? Portanto, o objetivo geral desta pesquisa consiste em identificar os custos e a formação do preço de venda dos produtos de uma indústria de panificação localizada no município de Arvoredo - SC.

A escolha do tema justifica-se pela necessidade de aprimorar os conhecimentos dos empreendedores (principalmente aqueles pequenos e micro que se utilizam apenas de conhecimentos empíricos para a gestão de seus negócios), permitindo apresentar algumas das ferramentas de custos que ensejam o controle e a evidenciação de informações úteis para a tomada de decisão dos investidores, gestores, contadores e sociedade em geral. Além disso, o setor da indústria de panificação apresenta-se em constante crescimento, sendo o setor alimentício de importância para a economia. Dessa forma, torna-se relevante estudar e calcular os custos e a formação do preço dos produtos deste segmento que envolve a transformação de fatores de produção em produto acabado.

Nesse sentido, este estudo se propõe apresentar o modelo de cálculo dos custos e a formação do preço de venda para pequenos empreendedores, servindo como fonte de dados primária às suas tomadas de decisões. Pesquisas com este viés, com abordagem clara e objetiva de cases reais, que procura abordar a desinformação dos pequenos empresários do setor de panificação, ainda são escassas. Corroboram este entendimento as pesquisas de Niemi e Jansik (2010), realizadas na Finlândia, onde os autores inferem que a técnica de mensuração e análises de preços mediante registros contábeis oferece muito mais detalhes e consistência da realidade de um segmento, embora exista uma forte relutância das empresas em divulgar seus dados, o que limita 
ou, geralmente, inviabiliza a pesquisa.

Dessa maneira, pretende-se, por meio desta pesquisa, diminuir esta assimetria informacional entre pequenos e grandes empreendedores, além de contribuir para o desenvolvimento de pesquisas relacionadas com esta temática.

Assim a pesquisa se propõe trazer subsídios para futuras pesquisas com foco em formação do preço de venda, podendo servir de amparo e parâmetro na aplicação dos resultados aqui encontrados em outros setores da economia nacional. Portanto, constitui uma abordagem de uma metodologia de formação de preço de venda de produtos no qual o modelo poderá ser replicado em outras empresas, auxiliando a projetar resultados que permitem aos tomadores de decisões menores achismos empíricos diante de decisões que resultam em consequências financeiras relevantes no curto e longo prazo para a organização. Neste viés, a presente pesquisa é de fundamental importância ao gestor do negócio e à comunidade cientifica.

Este estudo, além desta Introdução, está organizado em cinco seções, sendo que, na segunda seção, serão abordados os embasamentos conceituais necessários para o desenvolvimento da pesquisa. Após, na terceira seção, são abordados os aspectos metodológicos. Já na quarta seção, é apresentada a análise dos dados e, por fim, as considerações finais.

\section{REFERENCIAL TEÓRICO}

Neste tópico, apresenta-se a revisão da literatura que embasa o estudo. Abordam-se aspectos sobre a contabilidade de custos, a classificação dos custos, a formação do preço de venda e a aplicação do Mark up.

\subsection{Contabilidade de custos}

A contabilidade de custos é um ramo da contabilidade que produz informações para os diversos níveis gerenciais de uma entidade; auxilia as funções de determinação de desempenho, de planejamento e controle das operações e de tomada de decisão. 
Este ramo da contabilidade classifica, coleta e registra dados operacionais, denominados dados internos, e, em alguns casos, coleta e organiza dados externos da organização (Leone, 2000).

Entre as finalidades mais relevantes da contabilidade de custos, tem-se a avaliação dos estoques, o auxílio na determinação dos preços e, principalmente, o controle e a avaliação de desempenho de produtos/serviços ou unidades de negócios. Neste sentido, estas informações produzidas ensejam para os instrumentos gerenciais de planejamento e controle de uma organização (Lima, 2014). Tais finalidades são utilizadas pela empresa na otimização das decisões relativas ao gerenciamento amplo e profundo dos custos.

Com o forte aumento da concorrência entre empresas, em virtude da globalização e das recentes crises, as empresas foram obrigadas a dar mais atenção para a gestão dos custos como ferramenta de gestão estratégica de custos (Silva \& Lins, 2014).

Os custos podem ser classificados como diretos e indiretos, fixos e variáveis, dependendo de como são alocados aos produtos/serviços. Megliorini (2001) destaca que os custos indiretos são aqueles que não podem ser facilmente identificados e que necessitam de algum tipo de distribuição ou de rateio para serem alocados aos produtos. Ribeiro (2014) define que os custos diretos são aqueles que estão diretamente ligados à fabricação dos produtos, e sua determinação se dá em função de que, além de integrarem os produtos, suas quantidades e valores podem ser facilmente identificados em relação a cada produto.

Zanluca (2017) define como custos variáveis aqueles que variam proporcionalmente com o nível de produção ou atividades. Seus valores dependem do volume produzido ou de vendas efetivadas num período. Viceconti e Neves (2013) destacam que os custos fixos são aqueles cujos valores são os mesmos, independentemente do volume de produção da empresa ou, em caso de a empresa nada produzir, os custos fixos existirão da mesma forma. 
Existem vários métodos de custeio utilizados para distribuição e apropriação dos custos; no entanto, nesta pesquisa delimitaremos maior ênfase para o custeio por absorção e variável. O método de custeio por absorção consiste na apropriação de todos os custos de produção aos produtos elaborados de forma direta e indireta (Santos, 2009). Já para Leone (2000), o método de custeio variável é aquele que inclui, no custo das operações dos produtos, serviços e atividades, os custos diretos e variáveis. De modo geral, custeio significa apropriação de custos.

Percebe-se que a contabilidade de custos não se limita a atender somente a função de custear produtos para avaliação de estoques e determinação de lucros, mas também de gerar informações que permitam aos gestores se posicionarem quanto à eficiência e eficácia do processo produtivo e de sua capacidade de manutenção da continuidade rentável do empreendimento com as informações para controle e tomada de decisão (Almeida \& Santos, 2007).

\subsection{Formação do preço}

A correta formação do preço de venda é uma questão fundamental para a sobrevivência e o crescimento das empresas, independentemente do porte e da área de atuação. Com uma política eficiente de preços, as empresas podem atingir seus objetivos de lucro, crescimento em longo prazo, qualificação no atendimento dos clientes, dentre outras melhorias (Cunha \& Fernandes, 2007).

A preocupação em formar preços está ligada às condições de mercado, às características da concorrência, aos custos, ao nível de atividade e à remuneração do capital investido. A formulação do preço precisa apresentar para a empresa as possibilidades de maximização dos lucros, manter a qualidade dos produtos e atender os anseios do mercado (Santos, 2009). Mas deve-se ter cuidado na formação dos preços de acordo com o mercado, uma vez que o empresário poderá ter prejuízos, pois o preço praticado poderá gerar uma receita final que não cobre os custos da produção ou comercialização (Zahaikevitch \& Matos, 2013). 
Wernke (2005) argumenta que definir o preço é uma tarefa importante para os gestores, pois é por meio da formação do preço de venda que a empresa, efetivamente, passa a competir no mercado. Para fazer o cálculo do preço de venda corretamente, os gestores precisam ter em mente suas margens de lucratividade, de forma que os valores repassados ao consumidor final permitam cobrir seus custos básicos, trazendo resultados financeiros satisfatórios. O preço de venda deverá cobrir o custo do produto, as despesas variáveis, as despesas fixas e ainda sobrar um lucro líquido adequado (Lorentz, 2015).

O método para formar e analisar o preço deve ser aquele que melhor se adequar às necessidades da empresa. Dentre os métodos existentes, destaca-se o mark-up multiplicador, que contribui favoravelmente com a formação de preços compatíveis com as necessidades da empresa (Lorentz, 2015). Mas, ainda de acordo com Bruni e Famá (2011), existem duas outras formas de calcular o preço de venda de um produto ou serviço: Mark-up sobre o gasto variável que consiste na utilização sobre a somatória dos gastos variáveis da empresa, ou seja, os custos e despesas que variam. Porém somente poderá ser utilizado quando se conhece o preço de venda e a somatória dos seus gastos. Mark-up sobre o gasto total: O Mark-up é sobre os custos e despesas totais. Não é muito utilizado, pois muitas empresas não conseguem alocar os custos indiretos no custo do produto, e isso requer um grande esforço por parte da empresa.

O Mark-up é um multiplicador que se aplica sobre o custo da mercadoria ou serviço. É praticado com frequência para o cálculo dos preços de venda de forma rápida, e sua aplicação está ligada ao custo de aquisição ou produção. Integram o mark-up os impostos sobre as vendas (ICMS, ISS, PIS e COFINS) e lucros (IRPJ e CSLL), e também as despesas gerais, administrativas, comerciais e financeiras e 0 lucro desejado (Theiss \& Krieck, 2012).

Para Bruni e Famá (2011), quando se quer chegar ao preço de venda a ser praticado, aplica-se o mark-up sobre os gastos de determinado bem ou serviço, permitindo, assim, a formação do preço de venda. O mark-up pode ser empregado de diferentes formas: sobre os custos variáveis, sobre os gastos variáveis e sobre os 
Contabilidade de Custos e Formação do Preço de Venda: Um Estudo de Caso em uma Padaria Citania Aparecida Pilatti Bortoluzzi, Solange Chiossi, Tiago Francisco Camargo, Leossania Manfroi, Juliano Correa Daleaste

gastos integrais. A principal razão para sua aplicação se dá pelo fato de possibilitar uma grande simplificação do processo de formação do preço de venda. Para Morais e Vieira (2013), em empresas industriais, comerciais ou de serviços, a formação de preços é uma tarefa complexa em virtude de que formar preços envolve diversas áreas, entre elas marketing, economia, contabilidade de custos e finanças, que subsidiam as decisões dos gestores. Além disso, há diversas técnicas de formação de preços que visam maximizar a rentabilidade do negócio, seus impactos econômicos, bem como sua relação com os clientes. Podem-se destacar três delas: a precificação baseada em custos (mark-up); a precificação baseada na concorrência; e, por fim, a precificação com base no valor percebido pelos clientes.

Para Pinto (2011), o método baseado na concorrência preocupa-se com os concorrentes; seus preços são constituídos em consequência do praticado no mercado. Já com o método baseado no valor percebido pelo consumidor, é realizada uma investigação do quanto o cliente está disposto a pagar pelo produto. Em resumo, o consumidor é responsável pelo reajuste do preço, podendo variar o montante a ser pago de acordo com o público-alvo. Por fim, no método baseado no custo, os preços são formados com base nos custos da entidade e são classificados por serem formados de dentro para fora.

$\mathrm{Na}$ literatura internacional, conforme Niemi e Jansik (2010) sobre as técnicas de identificação dos preços e de suas margens, existem três técnicas amplamente utilizadas, sendo que a primeira consiste em analisar as tendências dos preços dos alimentos, correlacionando com a distribuição do preço de varejo pago pelo consumidor na cadeia alimentar. A segunda abordagem é o uso de preços comparativos. É muito utilizada em vários exames de preços e margens no setor de alimentos. Neste viés, Elitzak (1997), Reed e Clark (1998), Reed, Elitzak e Wohlgenant (2002), abordam que o Departamento de Agricultura dos Estados Unidos também emprega esta segunda técnica há muitos anos no cálculo de spreads de preços para uma variedade de produtos agrícolas. Ainda segundo Niemi e Jansik (2010), a terceira técnica muito utilizada é o uso dos registros contábeis internos das empresas. Essa abordagem 
Contabilidade de Custos e Formação do Preço de Venda: Um Estudo de Caso em uma Padaria

Citania Aparecida Pilatti Bortoluzzi, Solange Chiossi, Tiago Francisco Camargo, Leossania Manfroi,

Juliano Correa Daleaste

oferece muito mais detalhes, embora exista resistência das empresas em divulgar seus dados.

\section{METODOLOGIA}

Quanto aos objetivos, o presente estudo constitui-se de uma pesquisa exploratória. Segundo Raupp e Beuren (2004), busca-se, por meio do estudo exploratório, conhecer com profundidade o assunto e torná-lo mais claro ou construir questões importantes para a condução da pesquisa. Já na coleta de dados, foi utilizada a entrevista estruturada, observação e análise documental. Quanto à estratégia documental, consolida-se ao utilizar como fonte de dados informações e evidências, empregando fontes primárias de informações (Martins \& Theóphilo, 2016).

A pesquisa é caracterizada como estudo de caso pelo fato de considerar uma determinada unidade de análise específica, a qual permite levantar e examinar dados e fatos sem comprometer a realidade da qual está sendo verificada (Costa, 2004). Neste sentido, Yin (2001) reforça que o estudo de caso é a estratégia escolhida ao se examinar acontecimentos, e conta com duas fontes de evidências: a observação direta e série sistemática de entrevistas.

Para este estudo, foi escolhida como amostra intencional no setor panificação, sendo utilizada como instrumento de coleta de dados a entrevista semiestruturada, observação e análise documental. Barros e Lehfeld (2007) destacam que a entrevista é uma técnica que permite $o$ relacionamento estreito entre 0 entrevistador e 0 entrevistado, sendo que, na entrevista não estruturada, o pesquisador busca conseguir, por meio da conversação, os dados que possam ser utilizados na análise, buscando os aspectos que são mais relevantes para a pesquisa.

A entrevista foi realizada in loco em dois momentos: No primeiro momento diretamente com o proprietário para entender quais eram as metodologias $\mathrm{e}$ ferramentas de controle que o mesmo utilizava e como eram controlados os gastos indiretos de fabricação; Já para o segundo momento, direcionou-se a entrevista ao 
funcionário responsável pela produção, para se extrair os dados necessários ao desenvolvimento do estudo, como as fichas técnicas, tempo de produção, ciclo produtivo, quantidades produzidas. Após a coleta dos dados, os mesmos foram dispostos em planilhas do Exce/A. Na sequência, foi desenvolvida uma tabela para cada produto, o qual facilitou a leitura e análise dos dados.

Para apuração do custo total de produção, aplicou-se o método de custeio por absorção para que fossem analisados os dados, utilizando-se através de um mapa de custos alocando-os, em custos diretos e indiretos, para cada produto, a fim de encontrar o valor unitário por quilo em cada um dos produtos analisados e, posteriormente, formular o preço de venda ideal de acordo com as metas e objetivos planejados pelo empreendedor. Santos (2009) define que custeio por absorção consiste na apropriação de todos os custos de produção aos produtos elaborados de forma direta e indireta, os quais são causados pelo uso de recursos necessário para elaboração dos produtos. O uso do custeio de absorção se dá tendo em vista ser o sistema utilizado pela contabilidade. Com base no estudo de Eckert, Mecca, Biasio e Novello ( 2014), o custeio por absorção é o sistema mais utilizado quando se trata de sistema de custos integrado à contabilidade, além de ser o mais prático e adequado para os objetivos do estudo em questão. Ainda para Backes; Perleberg e Dalben (2007), o custo por absorção é o sistema adotado para determinar o custo integrado com a contabilidade e para determinar o custo do produto e dos estoques, tanto para fins societários como para fins fiscais.

Como técnica de análise e interpretação dos dados, utilizou-se a pesquisa quantitativa, a qual tem como objetivo principal quantificar ou mensurar uma ou mais variáveis estudadas, avaliar o comportamento de uma variável analisando a frequência com que ela ocorre e, a partir da análise dos resultados, busca explicar ou solucionar o fenômeno estudado (Casarin \& Casarin, 2012). 
Contabilidade de Custos e Formação do Preço de Venda: Um Estudo de Caso em uma Padaria

Citania Aparecida Pilatti Bortoluzzi, Solange Chiossi, Tiago Francisco Camargo, Leossania Manfroi, Juliano Correa Daleaste

\section{ANÁLISE DOS DADOS}

Neste tópico, é aplicado o modelo de mapa de custo por absorção, além de apresentar a caracterização da empresa e seu layout organizacional.

\subsection{Caracterização da Organização e Aplicação do Caso}

O estudo de caso trata de uma empresa de uma micro-empresa que possui 2 funcionários em tempo integral, sendo eles: o proprietário e um funcionário, o qual trabalha no processo produtivo. O layout do estabelecimento é composto por um espaço onde fica a produção e outro espaço para vendas.

A padaria em estudo está localizada na cidade de Arvoredo - SC, a qual iniciou suas atividades em 2013. Trabalha com um mix variado de produtos que ela mesmo produz, comercializa e, as vezes, distribui. O estudo foi realizado durante os meses de julho a outubro de 2017, no qual será observado o processo produtivo nesse período e será feita análise dos documentos e dos processos internos, os quais foram necessários para a realização da pesquisa.

Para atender os objetivos desta pesquisa, foram investigados apenas os três produtos mais representativos no faturamento global do empreendimento. Desta maneira, para fins de análise dos custos e da formação do preço de venda, consideraram-se os produtos: pão francês, cuca simples e bolacha de milho.

Quanto ao levantamento e mensuração dos custos, é necessária a utilização de operações matemáticas simples: soma, subtração, multiplicação, divisão e porcentagem (proporção) dos custos aos produtos. Os dados de custos foram organizados em planilhas eletrônicas, utilizando-se o programa Excel.

Dessa maneira, apresenta-se na Tabela 1 parte do layout da planta do empreendimento, sendo caracterizado pelo imobilizado e suas despesas com depreciações, utilizadas somente pela área de vendas e administrativa da padaria. 
Contabilidade de Custos e Formação do Preço de Venda: Um Estudo de Caso em uma Padaria

Citania Aparecida Pilatti Bortoluzzi, Solange Chiossi, Tiago Francisco Camargo, Leossania Manfroi, Juliano Correa Daleaste

Tabela 1

Imobilizado setor vendas/administrativo

\begin{tabular}{lccc}
\hline \multicolumn{1}{c}{ Imobilizado vendas/administrativo } & Valor & Depreciação anual & Depreciação mensal \\
\hline Expositor & $\mathrm{R} \$ 8.000,00$ & $\mathrm{R} \$ 800,00$ & $\mathrm{R} \$ 66,67$ \\
Bancada & $\mathrm{R} \$ 1.500,00$ & $\mathrm{R} \$ 150,00$ & $\mathrm{R} \$ 12,50$ \\
Computador & $\mathrm{R} \$ 3.000,00$ & $\mathrm{R} \$ 600,00$ & $\mathrm{R} \$ 50,00$ \\
Climatizador & $\mathrm{R} \$ 6.000,00$ & $\mathrm{R} \$ 600,00$ & $\mathrm{R} \$ 50,00$ \\
Móveis & $\mathrm{R} \$ 2.500,00$ & $\mathrm{R} \$ 250,00$ & $\mathrm{R} \$ 20,83$ \\
Utensílios & $\mathrm{R} \$ 900,00$ & $\mathrm{R} \$ 90,00$ & $\mathrm{R} \$ 7,50$ \\
Prédio & $\mathrm{R} \$ 30.000,00$ & $\mathrm{R} \$ 1.200,00$ & $\mathrm{R} \$ 100,00$ \\
Telefone (aparelho) & $\mathrm{R} \$ 115,00$ & $\mathrm{R} \$ 23,00$ & $\mathrm{R} \$ 1,92$ \\
Veículo & $\mathrm{R} \$ 30.000,00$ & $\mathrm{R} \$ 6.000,00$ & $\mathrm{R} \$ 500,00$ \\
\hline TOTAL & $\mathbf{R} \$ \mathbf{8 2 . 0 1 5 , 0 0}$ & $\mathbf{R} \$ \mathbf{9 . 7 1 3 , 0 0}$ & $\mathbf{R} \$ \mathbf{8 0 9 , 4 2}$ \\
\hline
\end{tabular}

Nota. Fonte: Conforme dados da pesquisa (2017).

A Tabela 1 refere-se ao investimento e a despesas totais com depreciação dos móveis, equipamentos e veículo utilizado pela área de vendas e administrativa da padaria, totalizando despesas fixas mensais de depreciação de $R \$ 809,42$. Sendo calculada por meio do método linear, de acordo com as taxas de depreciação, previstas pela Receita Federal do Brasil, de $20 \%$ ao ano para os equipamentos e veículo, e taxa de $10 \%$ ao ano para os móveis e utensílios, e $4 \%$ ao ano para o prédio. O valor da depreciação mensal será lançado como despesa mensal diretamente na demonstração do resultado por tratar-se de gastos não relacionados com o custo de produção. Tarifa e Silva (2009) definem despesa como sendo os gastos que ocorrem na obtenção da receita, os quais são necessários para vender e distribuir produtos. Na Tabela 2, é apresentado o imobilizado do setor de produção. 
Contabilidade de Custos e Formação do Preço de Venda: Um Estudo de Caso em uma Padaria Citania Aparecida Pilatti Bortoluzzi, Solange Chiossi, Tiago Francisco Camargo, Leossania Manfroi,

Tabela 2

Imobilizado setor de produção

\begin{tabular}{lccc}
\hline \multicolumn{1}{c}{ Imobilizado produção } & Valor & Depreciação anual & Depreciação mensal \\
\hline Utensílios & $\mathrm{R} \$ 2.100,00$ & $\mathrm{R} \$ 210,00$ & $\mathrm{R} \$ 17,50$ \\
Equipamentos & $\mathrm{R} \$ 39.000,00$ & $\mathrm{R} \$ 3.900,00$ & $\mathrm{R} \$ 325,00$ \\
Prédio & $\mathrm{R} \$ 70.000,00$ & $\mathrm{R} \$ 2.800,00$ & $\mathrm{R} \$ 233,33$ \\
\hline TOTAL & $\mathbf{R} \$ \mathbf{1 1 1 . 1 0 0 , 0 0}$ & $\mathbf{R} \$ \mathbf{6 . 9 1 0 , 0 0}$ & $\mathbf{R} \mathbf{5 7 5 , 8 3}$ \\
\hline
\end{tabular}

Nota. Fonte: Conforme dados da pesquisa (2017).

Observa-se, na Tabela 2, o valor do imobilizado, sendo que foi utilizada a depreciação linear, definida por Ribeiro (2013) como sendo a "aplicação de taxas constantes durante o tempo de vida útil estimado para o bem". O valor da depreciação mensal do imobilizado do setor de produção é de $R \$ 575,83$. Utilizou-se a taxa de depreciação de $10 \%$ ao ano para os utensílios e equipamentos e de $4 \%$ ao ano para o prédio.

$\mathrm{Na}$ Tabela 3, são evidenciados os valores dos custos indiretos relacionados à produção. Pode-se observar que a conta prédio possui valores distintos. Isso ocorre porque foi necessário fazer um rateio para distribuir a depreciação do prédio para a área de vendas/administrativo e para a produção. O valor total do prédio é de $\mathrm{R} \$$ $100.000,00$, sendo que foram distribuídos $30 \%$ para vendas/administrativo e $70 \%$ para produção. A Tabela 3 apresenta o rol de custos indiretos do setor de produção. 
Contabilidade de Custos e Formação do Preço de Venda: Um Estudo de Caso em uma Padaria

Citania Aparecida Pilatti Bortoluzzi, Solange Chiossi, Tiago Francisco Camargo, Leossania Manfroi, Juliano Correa Daleaste

Tabela 3

Custos indiretos setor de produção

\begin{tabular}{|c|c|c|c|c|c|c|}
\hline Descrição & Valor anual & Valor mensal & Vendas & Rateio & Produção & Rateio \\
\hline Seguro prédio & $\mathrm{R} \$ 648,00$ & $\mathrm{R} \$ 54,00$ & $R \$ 13,50$ & $25 \%$ & $\mathrm{R} \$ 40,50$ & $75 \%$ \\
\hline IPTU & $\mathrm{R} \$ 401,76$ & $\mathrm{R} \$ 33,48$ & $\mathrm{R} \$ 8,37$ & $25 \%$ & $\mathrm{R} \$ 25,11$ & $75 \%$ \\
\hline Material limpeza & $\mathrm{R} \$ 388,80$ & $\mathrm{R} \$ 32,40$ & $\mathrm{R} \$ 8,10$ & $25 \%$ & $\mathrm{R} \$ 24,30$ & $75 \%$ \\
\hline Contador & $\mathrm{R} \$ 1.053,00$ & $\mathrm{R} \$ 87,75$ & $\mathrm{R} \$ 14,04$ & $16 \%$ & $\mathrm{R} \$ 73,71$ & $84 \%$ \\
\hline Energia elétrica & $\mathrm{R} \$ 1.749,60$ & $\mathrm{R} \$ 145,80$ & $\mathrm{R} \$ 23,33$ & $16 \%$ & $\mathrm{R} \$ 122,47$ & $84 \%$ \\
\hline Dedetização & $\mathrm{R} \$ 252,72$ & $\mathrm{R} \$ 21,06$ & $\mathrm{R} \$ 5,27$ & $25 \%$ & $\mathrm{R} \$ 15,80$ & $75 \%$ \\
\hline Manutenção & $\mathrm{R} \$ 972,00$ & $\mathrm{R} \$ 81,00$ & $\mathrm{R} \$ 12,96$ & $16 \%$ & $\mathrm{R} \$ 68,04$ & $84 \%$ \\
\hline TOTAL & $R \$ 5.465,88$ & $R \$ 455,49$ & $\mathbf{R} \$ \mathbf{8 5 , 5 6}$ & & $R \$ 369,93$ & \\
\hline
\end{tabular}

Nota. Fonte: Conforme dados da pesquisa (2017).

Em relação aos custos fixos indiretos, é permitido que o gestor ou contador atribua bases de rateios e suas proporções para rateio das proporções, sendo que, para o seguro do prédio, IPTU, material de limpeza e dedetização, a base de rateio foi sobre a área total do prédio, ficando em $75 \%$ para a produção e $25 \%$ para vendas. Já para o custo com contador, energia elétrica e manutenção, a base de rateio utilizada foi o valor do imobilizado total, sendo distribuídos $84 \%$ para a produção e $16 \%$ para a área de vendas, representando um valor mensal total de $R \$ 455,49$.

$\mathrm{Na}$ Tabela 4, é apresentada a ficha técnica unitária para a produção de cada um dos três produtos, tendo como base apenas a relação da matéria prima constante da receita do pão francês, da cuca simples e da bolacha de milho, assim como suas respectivas quantidades e o custo total das mesmas. 
Contabilidade de Custos e Formação do Preço de Venda: Um Estudo de Caso em uma Padaria

Citania Aparecida Pilatti Bortoluzzi, Solange Chiossi, Tiago Francisco Camargo, Leossania Manfroi, Juliano Correa Daleaste

Tabela 4

Custos com matéria-prima

\begin{tabular}{|c|c|c|c|c|}
\hline \multicolumn{5}{|c|}{ Custos com matéria-prima do pão francês } \\
\hline Descrição & Unidade & Quantidade & Custo unitário & Custo total \\
\hline Farinha & KG & 10 & $\mathrm{R} \$ 1,50$ & $\mathrm{R} \$ 15,00$ \\
\hline Fermento & KG & 0,2 & $\mathrm{R} \$ 12,50$ & $R \$ 2,50$ \\
\hline Água & LT & 10 & $\mathrm{R} \$ 0,05$ & $\mathrm{R} \$ 0,50$ \\
\hline \multicolumn{5}{|c|}{ Material Secundário } \\
\hline Lenha & MT & 0,16 & $\mathrm{R} \$ 50,00$ & $\mathrm{R} \$ 8,00$ \\
\hline TOTAL & & & & $\mathbf{R} \$ \mathbf{2 6 , 0 0}$ \\
\hline \multicolumn{5}{|c|}{ Custos com matéria-prima da cuca simples } \\
\hline \multicolumn{5}{|l|}{ Massa } \\
\hline Descrição & Unidade & Quantidade & Custo unitário & Custo total \\
\hline Farinha & KG & 5 & $R \$ 1,50$ & $\mathrm{R} \$ 7,50$ \\
\hline Açúcar refinado & KG & 0,6 & $R \$ 3,00$ & $R \$ 1,80$ \\
\hline Sal & $K G$ & 0,05 & $\mathrm{R} \$ 2,00$ & $\mathrm{R} \$ 0,10$ \\
\hline Ovos & UND & 5 & $\mathrm{R} \$ 0,25$ & $\mathrm{R} \$ 1,25$ \\
\hline Margarina & $K G$ & 0,3 & $\mathrm{R} \$ 5,60$ & $\mathrm{R} \$ 1,68$ \\
\hline Adoçante & ML & 0,05 & $\mathrm{R} \$ 19,00$ & $\mathrm{R} \$ 0,95$ \\
\hline Erva doce & $K G$ & 0,05 & $\mathrm{R} \$ 11,00$ & $\mathrm{R} \$ 0,55$ \\
\hline Corante & $K G$ & 0,01 & $\mathrm{R} \$ 13,00$ & $\mathrm{R} \$ 0,13$ \\
\hline Aroma & $M L$ & 0,05 & $\mathrm{R} \$ 11,20$ & $\mathrm{R} \$ 0,56$ \\
\hline Fermento & $K G$ & 0,15 & $\mathrm{R} \$ 15,00$ & $R \$ 2,25$ \\
\hline Água & & 3 & $\mathrm{R} \$ 0,05$ & $\mathrm{R} \$ 0,15$ \\
\hline \multicolumn{5}{|c|}{ Material Secundário } \\
\hline Gás & $K G$ & 1,7 & $\mathrm{R} \$ 4,62$ & $\mathrm{R} \$ 7,85$ \\
\hline TOTAL & & & & $\mathbf{R} \$ 24,77$ \\
\hline \multicolumn{5}{|c|}{ Cobertura cuca simples } \\
\hline Descrição & Unidade & Quantidade & Custo unitário & Custo total \\
\hline Açúcar & $K G$ & 0,5 & $\mathrm{R} \$ 3,00$ & $\mathrm{R} \$ 1,50$ \\
\hline Margarina & $K G$ & 0,3 & $\mathrm{R} \$ 5,60$ & $\mathrm{R} \$ 1,68$ \\
\hline Farinha & $K G$ & 0,25 & $R \$ 1,50$ & $\mathrm{R} \$ 0,38$ \\
\hline Cachaça & $M L$ & 0,05 & $\mathrm{R} \$ 5,00$ & $\mathrm{R} \$ 0,25$ \\
\hline Total & & & & $\mathbf{R} \$ 3,81$ \\
\hline TOTAL DA RECEITA & & & & $\mathbf{R} \$ 28,58$ \\
\hline \multicolumn{5}{|c|}{ Custos com matéria-prima da bolacha de milho } \\
\hline Descrição & Unidade & Quantidade & Custo inicial & Custo total \\
\hline Ovos & UND & 12 & $\mathrm{R} \$ 0,33$ & $\mathrm{R} \$ 4,00$ \\
\hline Açúcar & KG & 1 & $\mathrm{R} \$ 2,00$ & $\mathrm{R} \$ 2,00$ \\
\hline Manteiga & $K G$ & 0,5 & $\mathrm{R} \$ 10,00$ & $R \$ 5,00$ \\
\hline Polvilho doce & KG & 1 & $\mathrm{R} \$ 8,50$ & $\mathrm{R} \$ 8,50$ \\
\hline
\end{tabular}

192 
Contabilidade de Custos e Formação do Preço de Venda: Um Estudo de Caso em uma Padaria

Citania Aparecida Pilatti Bortoluzzi, Solange Chiossi, Tiago Francisco Camargo, Leossania Manfroi,

Juliano Correa Daleaste

\begin{tabular}{lcccc}
\hline Fermento químico & $\mathrm{KG}$ & 0,06 & $\mathrm{R} \$ 7,50$ & $\mathrm{R} \$ 0,45$ \\
Farinha & $\mathrm{KG}$ & 2,5 & $\mathrm{R} \$ 1,50$ & $\mathrm{R} \$ 3,75$ \\
Farinha milho & $\mathrm{KG}$ & 0,25 & $\mathrm{R} \$ 3,60$ & $\mathrm{R} \$ 0,90$ \\
\hline \multicolumn{4}{c}{ Material Secundário } \\
\hline Lenha & $\mathrm{MT}$ & 0,14 & $\mathrm{R} \$ 50,00$ & $\mathrm{R} \$ 7,00$ \\
TOTAL & & & $\mathbf{R} \$ \mathbf{3 1 , 6 0}$ \\
\hline
\end{tabular}

Nota. Fonte: Conforme dados da pesquisa (2017).

$\mathrm{Na}$ Tabela 4, foram descritos os ingredientes utilizados no processo de produção de cada produto bem como sua unidade de medida e o custo de aquisição, além do material secundário utilizado no momento do cozimento de cada produto, apresentando a quantidade mensal e por porção de cada ingrediente.

Percebe-se que apenas três ingredientes são necessários para se produzir o pão francês. Isso se deve em função de que é utilizada a farinha com mistura pré-pronta, em que basta apenas adicionar a água e o fermento. $O$ custo da matéria-prima e do material secundário para uma receita do pão francês é de $R \$ 26,00$.

A cuca simples é, dentre os três produtos, a que mais tem ingredientes, pois são necessários ingredientes para a massa e para a cobertura, uma espécie de farofa, tendo um valor de $R \$ 28,58$.

A bolacha de milho é produto, dentre os três, que tem maior custo por receita, considerando os ingredientes e o material secundário, no valor de $\mathrm{R} \$ 31,60$. É importante salientar que todas as matérias-primas referenciadas para o processo produtivo foram avaliadas por meio do preço de mercado, sendo que qualquer alteração de valor afeta diretamente no custo unitário de cada produto que, por sua vez, impacta a política de preços e a lucratividade.

Na Tabela 5, são apresentados os custos com salários e encargos do funcionário responsável pela produção e o custo com salário do proprietário (pró-labore), o qual é responsável pelo setor de vendas/administrativo. O cálculo da mão de obra foi de acordo com a tributação da empresa, que está enquadrada no regime do Simples Nacional. 
Contabilidade de Custos e Formação do Preço de Venda: Um Estudo de Caso em uma Padaria

Citania Aparecida Pilatti Bortoluzzi, Solange Chiossi, Tiago Francisco Camargo, Leossania Manfroi,

Tabela 5

Custos com salários e encargos

\begin{tabular}{|c|c|}
\hline \multicolumn{2}{|l|}{ SALÁRIO SETOR DE PRODUÇÃO } \\
\hline Descrição & $\mathbf{R} \$$ \\
\hline Salário produção & $\mathrm{R} \$ 1.900,00$ \\
\hline FGTS parte empresa sobre folha do setor de produção & $\mathrm{R} \$ 152,00$ \\
\hline Provisão para férias com 1/3 sobre folha do setor de produção & $\mathrm{R} \$ 209,00$ \\
\hline Provisão para $13^{\circ}$ salário sobre folha do setor de produção & $\mathrm{R} \$ 158,27$ \\
\hline Provisão para multa rescisão FGTS $(4 \%+2,33 \%)$ sobre salário bruto & $R \$ 120,27$ \\
\hline TOTAL & $R \$ 2.539,54$ \\
\hline \multicolumn{2}{|c|}{ SALÁRIO SETOR VENDAS/ADMINISTRATIVO } \\
\hline Descrição & $\mathbf{R} \$$ \\
\hline Pró-labore & $\mathrm{R} \$ 937,00$ \\
\hline INSS (11\%) & $\mathrm{R} \$ 103,07$ \\
\hline TOTAL & $\mathrm{R} \$ 1.040,07$ \\
\hline
\end{tabular}

Nota. Fonte: Conforme dados da pesquisa (2017).

Conforme apresentado na Tabela 5, verifica-se que o custo total do salário do funcionário que trabalha no setor de produção é de $R \$ 2.539,54$, considerando o salário bruto e os encargos incidentes sobre o mesmo, os quais foram calculados conforme previsto na Consolidação das Leis do Trabalho. Já para a parte de vendas/administrativo, é o próprio proprietário responsável por esse setor. Assim temse apenas o pró-labore, o qual, na legislação trabalhista, não é equiparado ao salário, sendo que o empregador/proprietário pode conceder a si próprio um período de descanso remunerado bem como efetuar pagamento adicional e denominá-lo como $13^{\circ}$ salário, totalizando um custo de $R \$ 1 \cdot 040,07$. A Tabela 6 define o cálculo da formação do preço de venda dos três produtos. 
Contabilidade de Custos e Formação do Preço de Venda: Um Estudo de Caso em uma Padaria

Citania Aparecida Pilatti Bortoluzzi, Solange Chiossi, Tiago Francisco Camargo, Leossania Manfroi,

Tabela 6

Formação do preço de venda

\begin{tabular}{|c|c|c|c|c|}
\hline Impostos & $\%$ & Pão francês & Cuca simples & Bolacha milho \\
\hline IRPJ & $0,00 \%$ & & & \\
\hline CSLL & $0,00 \%$ & & & \\
\hline Cofins & $0,86 \%$ & & & \\
\hline PIS/PASEP & $0,00 \%$ & & & \\
\hline CPP & $2,75 \%$ & & & \\
\hline ICMS & $1,86 \%$ & & & \\
\hline TOTAL & $5,47 \%$ & $5,47 \%$ & $5,47 \%$ & $5,47 \%$ \\
\hline \multicolumn{2}{|l|}{ Margem Lucro Desejada } & $55 \%$ & $45 \%$ & $35 \%$ \\
\hline \multicolumn{2}{|l|}{ Total (\%) } & $60,47 \%$ & $50,47 \%$ & $40,47 \%$ \\
\hline \multicolumn{2}{|l|}{ Mak-up ( 1- (\%)) } & $39,53 \%$ & $49,53 \%$ & $59,53 \%$ \\
\hline \multicolumn{2}{|l|}{ Custo Unitário } & $R \$ 3,70$ & $\mathrm{R} \$ 4,99$ & $R \$ 10,35$ \\
\hline \multicolumn{2}{|c|}{ Formação do preço (custo unitário/Mark-up) } & $R \$ 9,36$ & $\mathrm{R} \$ 10,07$ & $\mathrm{R} \$ 17,39$ \\
\hline
\end{tabular}

Nota. Fonte: Conforme dados da pesquisa (2017).

A Tabela 6 apresentou a formação do preço de venda do pão francês, cuca simples e da bolacha de milho. Para se chegar ao preço, utilizou-se o mark-up multiplicador, considerando que a empresa deseja atingir uma margem de lucro de 55\% para o pão francês, $45 \%$ para a cuca simples e $35 \%$ para a bolacha de milho e, por se tratar de uma empresa optante pelo Simples Nacional, os impostos são de 5,47\% de acordo com tabela do Simples Nacional. Para que a padaria se enquadre como atividade de comércio, existe uma previsão legal de que, de acordo com a Receita Federal do Brasil (2007), os preparos, em padaria, confeitaria e pastelaria, de produtos alimentares não acondicionados em embalagens de apresentação, desde que vendidos diretamente ao consumidor final, não são considerados como produtos de industrialização.

Após encontrados os valores, é aplicado o Mark-up, o qual é feito da seguinte maneira: consideramos o pão francês para exemplo de cálculo 100\%-55\%-5,47\% = $39,53 \%$. Depois, é feito o seguinte cálculo: $3,70 / 39,53 \%=0,0936^{*} 100=R \$ 9,36$. 
Contabilidade de Custos e Formação do Preço de Venda: Um Estudo de Caso em uma Padaria

Citania Aparecida Pilatti Bortoluzzi, Solange Chiossi, Tiago Francisco Camargo, Leossania Manfroi, Juliano Correa Daleaste

Assim é encontrado o preço de venda para o pão (orientativo), e o mesmo cálculo deve ser aplicado para os demais produtos.

Para Wernke (2017), o Markup tem por finalidade cobrir tributos, despesas sobre vendas e despesas administrativas. Esses dados são essenciais para um bom gerenciamento de custos, pois, a partir deles, a empresa pode gerenciar com efetividade desde a sua margem de lucro até o preço final, conseguindo conhecer a margem de lucro desejada e comparar com a realidade da praticada pelo mercado.

A partir do preço de venda formulado, é possível fazer uma comparação entre o preço orientativo e o preço praticado pela padaria estudada em relação a cada produto, conforme a Tabela 7.

Tabela 7

Comparação entre preço orientativo e preço praticado

\begin{tabular}{lcccc}
\hline Produtos & $\begin{array}{c}\text { Preço de venda } \\
\text { orientativo }-\mathbf{K g}\end{array}$ & $\begin{array}{c}\text { Preço de venda } \\
\text { praticado- } \mathbf{K g}\end{array}$ & $\begin{array}{c}\text { Diferença \% entre } \\
\text { Pv orientativo e o } \\
\text { praticado }\end{array}$ & $\begin{array}{c}\text { Diferença (R\$)- } \\
\mathbf{K g}\end{array}$ \\
\hline $\begin{array}{l}\text { Pão francês } \\
\begin{array}{l}\text { Cuca } \\
\text { simples }\end{array}\end{array}$ & $\mathrm{R} \$ 9,36$ & $\mathrm{R} \$ 8,89$ & $-5,02 \%$ & $\mathrm{R} \$(0,47)$ \\
$\begin{array}{l}\text { Bolacha de } \\
\text { milho }\end{array}$ & $\mathrm{R} \$ 10,07$ & $\mathrm{R} \$ 8,75$ & $-13,11$ & $\mathrm{R} \$(1,32)$ \\
\hline
\end{tabular}

Nota. Fonte: Conforme dados da pesquisa (2017).

Verifica-se, na Tabela 7, que o preço de venda praticado por quilo $(\mathrm{kg})$ do pão francês, da cuca simples e da bolacha de milho é menor que o preço de venda orientativo, tendo uma diferença de $-5,02 \%$, o que representa $R \$ 0,47$ por quilo $(\mathrm{kg})$ para o pão francês, e de $-13,11 \%$ para a cuca simples, o que reflete em valores de $R \$$ 1,32 por quilo $(\mathrm{kg})$ vendido e de $\mathrm{R} \$ 0,41$ por quilo $(\mathrm{kg})$ para a bolacha de milho. Assim, a cuca simples é o produto, dentre os três produtos analisados, que mais tem diferença entre o preço praticado e o preço orientativo. No entanto, o produto mais vendido e mais representativo no faturamento é o Pão Francês. Na sequência, por meio da Tabela 8, é demonstrada a apuração do resultado do exercício. 
Contabilidade de Custos e Formação do Preço de Venda: Um Estudo de Caso em uma Padaria

Citania Aparecida Pilatti Bortoluzzi, Solange Chiossi, Tiago Francisco Camargo, Leossania Manfroi, Juliano Correa Daleaste

Tabela 8

Demonstração do Resultado do Exercício - Anual

\begin{tabular}{|c|c|c|c|c|}
\hline & Pão francês & Cuca simples & Bolacha milho & Valor total \\
\hline ( $=$ RECEITA OPERACIONAL BRUTA & $\mathrm{R} \$ 10.134,60$ & $R \$ 1.312,50$ & $\mathbf{R} \$ 509,40$ & $\mathbf{R} \$ 11.956,50$ \\
\hline (-) DEDUÇÕES DA RECEITA BRUTA & $\mathrm{R} \$ 554,36$ & $\mathbf{R} \$ 71,79$ & $\mathbf{R} \$ 27,86$ & $\mathrm{R} \$ 654,02$ \\
\hline (-) Impostos & $\mathrm{R} \$ 554,36$ & $\mathrm{R} \$ 71,79$ & $\mathbf{R} \$ 27,86$ & $\mathrm{R} \$ 654,02$ \\
\hline (-) CPP $(2,75 \%)$ & $\mathrm{R} \$ 278,70$ & $\mathrm{R} \$ 36,09$ & $\mathrm{R} \$ 14,01$ & $\mathrm{R} \$ 328,80$ \\
\hline (-) Cofins $(0,86 \%)$ & $\mathrm{R} \$ 87,16$ & $\mathrm{R} \$ 11,29$ & $\mathrm{R} \$ 4,38$ & $R \$ 102,83$ \\
\hline (-) ICMS (1,86\%) & $\mathrm{R} \$ 188,50$ & $\mathrm{R} \$ 24,41$ & $\mathrm{R} \$ 9,47$ & $\mathrm{R} \$ 222,39$ \\
\hline (=) RECEITA OPERACIONAL LÍQUIDA & $\mathrm{R} \$ 9.580,24$ & $R \$ 1.240,71$ & $\mathrm{R} \$ \mathbf{4 8 1 , 5 4}$ & $\mathrm{R} \$ 11.302,48$ \\
\hline (-) CUSTOS DAS VENDAS & $\mathrm{R} \$ \mathbf{4 . 2 1 8 , 0 0}$ & $\mathbf{R} \$ \mathbf{7 4 8 , 5 0}$ & $\mathbf{R} \$ \mathbf{3 1 0 , 5 0}$ & $\mathrm{R} \$ \mathbf{5 . 2 7 7 , 0 0}$ \\
\hline (=) RESULTADO OPERACIONAL BRUTO & $\mathrm{R} \$ 5.362,24$ & $R \$ 492,21$ & $R \$ 171,04$ & $\mathrm{R} \$ 6.025,48$ \\
\hline (-) DESPESAS OPERACIONAIS & $\mathrm{R} \$ 1.869,25$ & $R \$ 245,89$ & $R \$ 49,13$ & $\mathrm{R} \$ 2.164,39$ \\
\hline (-) Despesas administrativas & $\mathrm{R} \$ \mathbf{9 8 4 , 5 6}$ & $R \$ 129,51$ & $R \$ 25,88$ & $R \$ 1.140,07$ \\
\hline (-) Despesas com telefone/internet & $\mathrm{R} \$ 56,13$ & $\mathrm{R} \$ 7,38$ & $\mathrm{R} \$ 1,48$ & $\mathrm{R} \$ 65,00$ \\
\hline (-) Despesas com material escritório & $\mathrm{R} \$ 30,23$ & $\mathrm{R} \$ 3,98$ & $\mathrm{R} \$ 0,79$ & $\mathrm{R} \$ 35,00$ \\
\hline (-) Pro labore & $\mathrm{R} \$ 898,20$ & $\mathrm{R} \$ 118,15$ & $\mathrm{R} \$ 23,61$ & $\mathrm{R} \$ 1.040,07$ \\
\hline (-) Despesas com vendas & $\mathbf{R} \$ \mathbf{8 8 4 , 6 9}$ & $R \$ 116,37$ & $R \$ 23,25$ & $\mathrm{R} \$ \mathbf{1 . 0 2 4 , 3 2}$ \\
\hline (-) Despesas com depreciação & $\mathrm{R} \$ 699,02$ & $\mathrm{R} \$ 91,95$ & $\mathrm{R} \$ 18,37$ & $\mathrm{R} \$ 809,42$ \\
\hline (-) Despesas com embalagens & $\mathrm{R} \$ 95,00$ & $\mathrm{R} \$ 12,50$ & $\mathrm{R} \$ 2,50$ & $\mathrm{R} \$ 110,00$ \\
\hline (-) Despesas com combustível & $\mathrm{R} \$ 90,68$ & $\mathrm{R} \$ 11,93$ & $\mathrm{R} \$ 2,38$ & $\mathrm{R} \$ 105,00$ \\
\hline (=) LUCRO LÍQ. ANTES PARTICIPAÇÕES & $\mathrm{R} \$ 3.492,98$ & $\mathrm{R} \$ 246,32$ & $\mathbf{R} \$ 121,90$ & $\mathrm{R} \$ 3.861,21$ \\
\hline (=) RESULTADO LÍQUIDO DO EXERCíCIO & $\mathrm{R} \$ \mathbf{3 . 4 9 2 , 9 8}$ & $\mathrm{R} \$ 246,32$ & $R \$ 121,90$ & $\mathrm{R} \$ 3.861,21$ \\
\hline
\end{tabular}

Nota. Fonte: Conforme dados da pesquisa (2017).

Conforme a Tabela 8, apresenta-se a demonstração do resultado do exercício gerencial, pois está estruturada por produto e que, segundo Hong (2006), é desenvolvida para atender as necessidades de planejamento, controle e avaliação de desempenho, voltada para o público interno da organização.

A receita operacional bruta de cada produto foi calculada considerando-se o preço de venda praticado, o qual foi multiplicado pelo total de quilos vendidos durante o mês, sendo $1.140 \mathrm{Kg}$ vendidos de pão francês, $150 \mathrm{Kg}$ de cuca simples e $30 \mathrm{Kg}$ de bolacha de milho. Na dedução de vendas, os impostos estão de acordo com o Simples 
Nacional. Para a formação do custo do produto vendido, utilizam-se as quantidades vendidas no mês de cada produto multiplicado pelo custo unitário.

Nas despesas operacionais, constam as despesas administrativas e de vendas que, por se tratarem de gastos feitos pela empresa e que não compõem o custo dos produtos, são consideradas despesas operacionais. Na despesa administrativa, tem-se o gasto com telefone/internet, material de escritório e o pró-labore, totalizando um valor mensal de $R \$ 1 \cdot 140,07$. Para as despesas de vendas, o gasto é com depreciação do imobilizado, combustível e embalagens, valor mensal de $R \$ 1.024,32$.

O resultado líquido do mês em estudo para o pão francês foi de $R \$ 3.492,98$, para a cuca simples $R \$ 246,32$ e de $R \$ 121,90$ para bolacha de milho. É um total mensal de $R \$ 3.861,21$, considerando a soma do resultado líquido dos três produtos.

O empresário, ao analisar a demonstração do resultado, saberá quais os produtos que estão tendo mais lucro ou prejuízo, podendo, assim, focar em determinado produto para melhorar seu resultado ou, até mesmo, alavancar as vendas daquele produto que tem um bom resultado, a fim de aumentar a lucratividade.

Por meio da Tabela 9, é demonstrado o resultado do exercício pelo preço de venda orientativo. Após, será comparado com o resultado do exercício pelo preço de venda praticado. 
Contabilidade de Custos e Formação do Preço de Venda: Um Estudo de Caso em uma Padaria

Citania Aparecida Pilatti Bortoluzzi, Solange Chiossi, Tiago Francisco Camargo, Leossania Manfroi,

Juliano Correa Daleaste

Tabela 9

Demonstração do Resultado do Exercício pelo preço de venda orientativo

\begin{tabular}{|c|c|c|c|c|c|c|}
\hline & Pão francês & $\begin{array}{c}\text { Cuca } \\
\text { simples }\end{array}$ & $\begin{array}{c}\text { Bolacha } \\
\text { milho }\end{array}$ & Total & $\begin{array}{c}\text { Variação } \\
\mathbf{R} \$\end{array}$ & $\begin{array}{c}\text { Variação } \\
\%\end{array}$ \\
\hline \multirow{2}{*}{$\begin{array}{l}\text { Quantidade } \\
\text { produzida mês } \\
\text { Preço de venda } \\
\text { sugerido }\end{array}$} & 1140 kg & $150 \mathrm{~kg}$ & $30 \mathrm{~kg}$ & & & \\
\hline & $R \$ 9,36$ & $\mathrm{R} \$ 10,07$ & $\mathrm{R} \$ 17,39$ & & & \\
\hline \multirow{2}{*}{$\begin{array}{l}\text { (=) Receita bruta } \\
\text { (-) Impostos sobre } \\
\text { vendas }\end{array}$} & $\mathrm{R} \$ 10.670,40$ & $\mathrm{R} \$ 1.510,00$ & $\mathrm{R} \$ 521,70$ & $\mathrm{R} \$ 12.702,60$ & $\mathrm{R} \$ 746,10$ & $5,9 \%$ \\
\hline & $\mathrm{R} \$ 583,67$ & $\mathrm{R} \$ 82,62$ & $\mathrm{R} \$ 28,54$ & $\mathrm{R} \$ 694,83$ & $\mathrm{R} \$ 40,81$ & $5,9 \%$ \\
\hline \multirow{5}{*}{$\begin{array}{l}\text { (=) Receita líquida } \\
\text { (-) Custo produto } \\
\text { vendido } \\
\text { (=) Resultado } \\
\text { bruto } \\
\text { (-) Despesas } \\
\text { administrativas } \\
\text { (-) Despesas } \\
\text { vendas }\end{array}$} & $\mathrm{R} \$ 10.086,73$ & $\mathrm{R} \$ 1.427,88$ & $\mathrm{R} \$ 493,16$ & $\mathrm{R} \$ 12.007,77$ & $\mathrm{R} \$ 705,29$ & $5,9 \%$ \\
\hline & $\mathrm{R} \$ 4.218,00$ & $\mathrm{R} \$ 748,50$ & $\mathrm{R} \$ 310,50$ & $\mathrm{R} \$ 5.277,00$ & $R \$-$ & $0 \%$ \\
\hline & $\mathrm{R} \$ 5.868,73$ & $\mathrm{R} \$ 679,38$ & $\mathrm{R} \$ 182,66$ & $\mathrm{R} \$ 6.730,77$ & $\mathrm{R} \$ 705,29$ & $10,5 \%$ \\
\hline & $\mathrm{R} \$ 984,56$ & $\mathrm{R} \$ 129,51$ & $\mathrm{R} \$ 25,88$ & $\mathrm{R} \$ 1.140,07$ & $\mathrm{R} \$$ - & $0 \%$ \\
\hline & $\mathrm{R} \$ 884,69$ & $\mathrm{R} \$ 116,37$ & $\mathrm{R} \$ 23,25$ & $\mathrm{R} \$ 1.024,32$ & $\mathrm{R} \$-$ & $0 \%$ \\
\hline (=) Lucro líquido & $\mathrm{R} \$ 3.999,48$ & $R \$ 433,49$ & $R \$ 133,53$ & $\mathrm{R} \$ 4.566,50$ & $R \$ 705,29$ & $14,6 \%$ \\
\hline
\end{tabular}

Nota. Fonte: Conforme dados da pesquisa (2017).

Com base na Tabela 9, são apresentados os possíveis resultados auferidos pela utilização do sistema de custeio por absorção e o que este influenciou diretamente no resultado global da empresa, conforme disposto na DRE gerencial.

O primeiro ponto a ser considerado é o preço de venda praticado versus o preço de venda orientativo, em que, conforme os resultados da análise, o empresário está praticando preços menores (subavaliados) com relação aos preços sugeridos pelo Mark-up e no seu planejamento estratégico (identificado na entrevista) para os três produtos.

Na prática, a cada quilo vendido do produto pão francês, o empresário deixa de ganhar $R \$ 0,47$, e $R \$ 1,32$ na cuca simples, assim como $R \$ 0,41$ na bolacha de milho. É relevante considerar que, pelo total de quilos vendidos no mês (meta), somente no pão francês a empresa deixa de gerar lucro líquido de $R \$ 535,80$ mensal ou $14,51 \%$ menor lucro neste produto. 
Esses resultados vêm ao encontro dos evidenciados na pesquisa de Rocha Oliveira, Soares, Silva, Oliveira, Valdevino e Oliveira (2019), em que os autores procuraram comparar os resultados dos preços praticados em uma grande empresa de panificação com aqueles apurados devidamente por meio do Mark-up. Em sua pesquisa, os autores identificaram que, de todo o mix de produto analisado, apenas no pão francês a empresa estava comercializando com preço superior ao orientativo. De maneira geral, em todos os demais itens a empresa estava comercializando a valores que produziam margens de contribuição abaixo do esperado pelos gestores (investidores).

O segundo ponto analisado trata dos impostos sobre as vendas. Tomando-se como base os impostos sobre a receita bruta pelo preço de venda praticado, o empresário economiza $R \$ 40,81$ por mês, ou seja, $5,9 \%$ a menos do que pagaria se vendesse os produtos pelo preço orientativo. No entanto, mesmo tendo uma certa "economia" nos impostos, nada se equivale ao valor que se está deixando de ganhar, ou seja, $\mathrm{R} \$ 746,10$ ao mês, considerados os três produtos.

Com relação ao valor dos custos mensais referentes aos CPVs, este representou $\mathrm{R} \$ 5.277,00$, sendo que o produto com maior demanda que necessita de investimentos em matéria-prima (capital de giro) de $R \$ 4.218,00$ foi o pão francês, e o que necessita de menores investimentos em matéria prima foi a bolacha de milho, com apenas $R \$$ 310,50 de CPV. Já com relação ao total das despesas operacionais (venda e entrega) mensais, o valor gasto foi de $R \$ 2.164,39$.

Em relação ao lucro líquido do período, a padaria seria mais lucrativa e mais eficiente se adotasse o preço de venda orientativo, pois comprovou-se que o uso e o conhecimento das informações de custos e a correta precificação podem auxiliar os empreendedores a melhorar a lucratividade de seus negócios, assim como a tomada de decisão entre produzir ou não determinado produto em seu mix. O que ficou comprovado através do resultado líquido do DRE: utilizando-se o preço de venda praticado com o preço de venda orientativo, existe uma perda de lucro de $14,6 \%$ ao mês. 
Quanto à margem de lucro líquida, que é implementada na formação do preço de venda, a padaria também tem perda por não praticar o preço de venda ideal, pois quanto maior for a margem de contribuição em cada produto, maior será a sobra da padaria após o recebimento das vendas, da retirada dos impostos e das deduções. Verificou-se que há uma redução de margem líquida de 3\% para o pão francês, 10\% na cuca simples e $2 \%$ na bolacha de milho. Dentre os três produtos analisados, a cuca simples foi o que apresentou a maior diferença na margem líquida, deixando de lucrar $\mathrm{R} \$ 187,17$ com esse produto.

Em relação aos níveis de despesas operacionais, considerando as despesas de vendas e administrativas, as mesmas permanecem iguais em valores $(R \$)$, mas se alteram na proporção (\%). Constitui a menor proporção de despesa na DRE pelo preço orientativo, representando $15,9 \%$ do total da receita, enquanto que, com a DRE utilizando o preço praticado, o nível de despesa alcança $16,9 \%$ do total.

Em relação à variação total do lucro líquido, observa-se que, por não estar sendo praticado o preço de venda orientativo, existe uma diminuição no lucro líquido de 14,6 $\%$. Isso quer dizer que a todo mês o empresário deixa de lucrar $R \$ 705,29$.

A partir dessas análises, pode-se afirmar que a correta precificação do custo e de preço de venda permite melhorar todos os indicadores da DRE de um empreendimento. Dessa forma, constata-se que, durante o ano, a variação total acumulada do lucro líquido que deixou de ser auferida é de $R \$ 8.463,48$, podendo ser um valor bem significativo para uma empresa pequena.

De maneira geral, o único ponto que se torna satisfatório em vender com preço subavaliado, do ponto de vista do empreendedor, é o valor dos impostos pago. Porém, como já salientado, o valor financeiro não é relevante diante do que o empresário está deixando de lucrar. É importante ressaltar que o empresário não está tendo prejuízo com o preço de venda que ele está praticando; no entanto, não está obtendo o retorno do lucro que deseja. 
Contabilidade de Custos e Formação do Preço de Venda: Um Estudo de Caso em uma Padaria

Citania Aparecida Pilatti Bortoluzzi, Solange Chiossi, Tiago Francisco Camargo, Leossania Manfroi, Juliano Correa Daleaste

\section{CONSIDERAÇÕES FINAIS}

O presente estudo teve como objetivo geral identificar os custos e a formação do preço de venda dos produtos de uma indústria de panificação localizada no município de Arvoredo - SC. Para tanto, foi utilizada a técnica do estudo de caso, o qual evidenciou a relevância de se ter uma assessoria e acompanhamento no conhecimento de todos os custos de um empreendimento, seja ele grande ou pequeno (micro). Entende-se que a pesquisa atendeu ao seu objetivo geral, pois permitiu identificar os custos e a influência do preço de venda que um produto ou serviço têm no resultado final de uma atividade e, consequentemente, na tomada de decisão.

A empresa em estudo não possuía nenhuma ficha de controle para gerenciar os custos em relação aos produtos. Contudo, o empresário está praticando preços abaixo do ideal nos três produtos analisados. Entretanto, não está tendo prejuízo, apenas não tem o retorno de lucro que deseja.

Com isso, conclui-se que o conhecimento dos custos é um fator essencial na vida do empreendedor (investidor) e para a sobrevivência de qualquer empresa. A elaboração correta do preço de venda garante o lucro que os proprietários almejam auferir, permitindo que, caso apresentada uma otimização dos resultados líquidos de $14,6 \%$, o que pode ser significativo no resultado global.

Como limitações do estudo, destacam-se as dificuldades em encontrar a base ou os critérios de rateio dos custos indiretos relacionados a cada produto, pelo fato de a padaria não dispor de dados internos organizados para isso e por haver um mix de produtos superior ao estudado, além do fato de o próprio empresário não ter conhecimento sobre custos indiretos.

Como sugestões para pesquisas futuras, orienta-se verificar se seria mais vantajoso para uma padaria comprar o pão francês pré-pronto e apenas assá-lo para comercialização, ou manter a linha de produção. 
Contabilidade de Custos e Formação do Preço de Venda: Um Estudo de Caso em uma Padaria

Citania Aparecida Pilatti Bortoluzzi, Solange Chiossi, Tiago Francisco Camargo, Leossania Manfroi,

Juliano Correa Daleaste

\section{REFERÊNCIAS}

Almeida, L. B. de., Santos, A. R. (2007). Práticas de contabilidade de custos: uma investigação nas indústrias Paranaenses. Sociedade, Contabilidade e Gestão, 2(1), 19-34.

Backes, R. G., Perleberg, C. R., \& Dalben, L. C. (2007). Aplicação do método de custeio RKW em uma cooperativa agrícola. Custos e @gronegócio on line, 3, 18-39. https://doi.org/10.24425/118183.

Barros, A. J. S., Lehfeld, N. A. S. (2007). Fundamentos de metodologia científica. 3. ed. São Paulo: Pearson Prentice Hall.

Bruni, A. L., Famá, R. (2011). Gestão de custos e formação de preços: com aplicações na calculadora HP 12C e Excel. (5a ed.). São Paulo: Atlas.

Casarin, H. C. S., Casarin, S. J. (2012). Pesquisa científica: da teoria à prática. Curitiba: InterSaberes.

Costa, O. S. da. (2004). Estudo de Caso na Produção da Panificadora Orlessan Orlando. In: Universidade Federal de Santa Catarina, Centro Sócio-Econômico, Departamento de Ciências Econômicas, Curso de Graduação em Ciências Econômicas Estudo.

Cunha, M. C. F., \& Fernandes, M. S. A. (2007). A utilização da contabilidade de custos na formação do preço de venda. Anais do $X$ ENCONTRO DE INICIAÇÃO À DOCÊNCIA. UFPB - PRG. Recuperado em 04 março, 2017, de: <http://www.classecontabil.com.br/artigos/a-utilizacao-dacontabilidade-de-custos-na-formacao-do-preco-de-vendas.

Eckert, A., Mecca, M. S., Biasio, R., \& Novello, E. (2014). Alocação dos custos indiretos de fabricação: impactos no custo final e na fixação de preços de venda em uma empresa de serviços de pintura automotiva. RIC - Revista de Informação Contábil, $8(2), 1-28$.

Elitzak, H. (1997). Food Cost Review, 1996. U.S. Department of Agriculture, Economic Research Service, AER-761.

Filho, L. L. S., Lagioia, U. C. T., Araújo, J. G. N., Araujo, J. G., \& Filho, F. A. C. (2015). "Gestão de custos e formação de preço de venda, gestão de caixa e gestão de riscos: um estudo exploratório no arranjo produtivo local gesseiro do estado de Pernambuco". ABCustos 10(3), 107-42. 
Contabilidade de Custos e Formação do Preço de Venda: Um Estudo de Caso em uma Padaria Citania Aparecida Pilatti Bortoluzzi, Solange Chiossi, Tiago Francisco Camargo, Leossania Manfroi,

Hall, R. J., Costa, V. C., Kreuzberg, F., Moura, G. D., \& Hein, N. (2012). Contabilidade como uma ferramenta da gestão: um estudo em micro e pequenas empresas do ramo de comércio de Dourados-MS. Revista da Micro e Pequena Empresa, Campo Limpo Paulista, 6(3), 4-17.

Hong, Y. C. (2006). Contabilidade gerencial. São Paulo: Pearson Prentice Hall.

Leone, J. S. G. (2000). Curso de contabilidade de custos. (2a ed.). São Paulo: Atlas.

Lima, E. B. Contabilidade de custos. (2014). Conselho Regional de Contabilidade do Estado do Rio de Janeiro.

Lorentz, F. (2015). Contabilidade e análise de custos: uma abordagem prática e objetiva: 250 exercícios resolvidos. Rio de Janeiro: Freitas Bastos.

Martins, G. A., \& Theóphilo, C. R. (2016). Metodologia da investigação cientifica para ciências sociais e aplicadas. (3a ed.). Atlas: São Paulo.

Megliorini, E. (2001). Custos. São Paulo: Makron Books.

Megliorini, E. (2012). Custos: análises e gestão. (2a. ed.). São Paulo: Pearson Prentice Hall.

Morais, J. F., \& Vieira, E. P. (2013). Estratégias de precificação para empresas comerciais. ljuí.

Niederle, F. (2012). Sistema de custos e análise de preços na padaria Bom Gosto. (Trabalho de Conclusão do Curso Ciências Contábeis). Universidade Regional do Noroeste do Estado Do Rio Grande do Sul, Unijuí, Três Passos, RS, Brasil.

Niemi, Jyrki et al. (2010, June). Price formation and margin behaviour in the Finnish food markets. Anais do 21st Annual IFAMA World Symposium. Frankfurt. 20-31, 21.

Pelissari, A. S., Gonzalez, I. V. D. P., \& Vanalle, R. M. (2011). Competências gerenciais: Um estudo em pequenas empresas de Confecções. Revista Eletrônica de Administração, 17(1), 149-180.

Pinto, L. J. S. (2011). Formação do Preço de Venda com Base no Lucro Desejado: um Estudo de Caso através do Mapeamento dos Custos e Despesas. Anais do VIII SEGeT - Simpósio de Excelência em Gestão e Tecnologia, Resende, RJ, Brasil, 8. 
Contabilidade de Custos e Formação do Preço de Venda: Um Estudo de Caso em uma Padaria

Citania Aparecida Pilatti Bortoluzzi, Solange Chiossi, Tiago Francisco Camargo, Leossania Manfroi, Juliano Correa Daleaste

Raupp, M. F., \& Beuren, I. M. (2004). Metodologia de Pesquisa Aplicável às Ciências Sociais. In: Beuren, Ilse Maria. Como elaborar trabalhos monográficos em contabilidade: teoria e prática. (2a ed.). São Paulo: Altas.

Reed, A. J., \& J. S. Clark. (1998). Nonfarm Input Prices, Price Margins, and Consumer Food Prices. S. Department of Agriculture, Economic Research Service, Technical Bulletin, 1867.

Reed, A., Elitzak, H., \& Wohlgenant, M. (2002). Retail-Farm Price Margins and Consumer Product Diversity. U.S. Department of Agriculture, Economic Research Service, Technical Bulletin No. 1899.

Receita Federal Do Brasil (RFB). (2007). Solução de consulta no 341, de 26 de setembro de 2007, DOU de 02.10.2007. Recuperado em 14 outubro, 2017 de $<$ http://blog.esimplesauditoria.com.br/panificadoras-optantes-pelo-simplesindustria-ou-comercio/:>.

Ribeiro, O. M. (2013). Contabilidade comercial fácil. (18a ed.). São Paulo: Saraiva.

Ribeiro. (2014). Contabilidade de custos fácil. (9a ed.). São Paulo: Saraiva.

Rocha, I. C., Oliveira, A. M., Soares, F. I. L., Silva, G. V., Oliveira, A. M., Valdevino, R. Q. S., \& Oliveira, M. C. S. (2019, sep). Cost acoounting as a tool in sales price formation in a bakery industry. Braz. J. of Develop., Curitiba, 5(9), 15957-15980.

Santos, J. J. (2009). Contabilidade e análise dos custos: modelo contábil, métodos de depreciação, $A B C$ - custeio baseado em atividades, análise atualizada de encargos sociais sobre salários. (5a ed.). São Paulo: Atlas.

Serviço Brasileiro de Apoio às Micro e Pequenas Empresas - SEBRAE (2018). Panificadoras oferecem oportunidades para quem investir em inovação. Recuperado em 15 março, 2020, de <https://blog.sebrae-sc.com.br/panificadorasoferecem-oportunidades-para-quem-investir-em-inovacao/>.

Sepp, C., Manfroi, L., Theisen, C. P., Diel, H. E., \& Diel, J. F. (2015). Formação do preço de venda: um estudo aplicado em um restaurante do município de ChapecóSC. Revista Cientifica Tecnológica 3(2), 105-21.

Silva, R. N. S., \& Lins, L. S. (2014). Gestão de custos: contabilidade, controle e análise. (3a ed.). São Paulo: Atlas.

Tarifa, M. R., \& Silva, L. F. S. (2009). Contabilidade gerencial: ciências contábeis. São Paulo: Pearson Education do Brasil. 
Theiss, J. R., \& Krieck, M. (2012). Custos e preços sugeridos de vendas: cálculos e enfoques práticos, serviços, comércio e indústria. (4a ed.). Blumenau: Odorizzi.

Viceconti, P., \& Neves, S. (2013). Contabilidade de custos: um enfoque direto e objetivo. (11a ed.). rev. e atual. São Paulo: Saraiva.

Zahaikevitch, E. V., \& Matos, S. N. (2013). Formação de preço de venda em Micro e Pequenas empresas: um estudo de caso nas empresas do ramo de informática em uma cidade do interior do Parará. Facesi em Revista, 5(1).

Zanluca, J. S. (2017). Custos fixos e variáveis. Recuperado em 26 março, 2017, de <http://www.portaldecontabilidade.com.br/tematicas/custo-fixo-variavel.htm>.

Wernke, R. Análise de custos e preços de venda. (11a ed.). São Paulo: Saraiva, 2017.

Wernke, R. (2005). Análise de custos e preços de venda: ênfase em aplicações e casos nacionais. São Paulo: Saraiva.

Yin, R. K. (2001). Estudo de caso: planejamento e métodos. Trad. Daniel Grassi (2a ed.). Porto Alegre: Bookman.

Data de Submissão: 03/11/2019

Data de Aceite: 17/04/2020 